\title{
$O$ contexto europeu de formação e atuação na passagem do século XIX para o XX
}

\author{
Umberto Cerasoli Júnior \\ Doutorando em Artes Cênicas/USP \\ Área de Concentração: Pedagogia do Teatro \\ Orientador: Armando Sérgio da Silva \\ Membro do Centro de Pesquisas em Experimentação Cênica do Ator, da ECA/USP
}

Resumo: este artigo tem como objetivo apresentar o modelo de atuação e formação do ator adotado na Europa no final do século XIX, para contextualizar o ambiente teatral contra o qual os principais renovadores teatrais do século $\mathrm{XX}$ se insurgiram. Na parte final, destacamos, sucintamente, as contribuições que François Delsarte, Émilie Jacques-Dalcroze e o Teatro Oriental ofereceram para essa renovação.

Palavras-chave: renovação teatral, teatro século XIX

Title: The european context of action and training in the passage of the 19th to the 20th Century Abstract: this article aims to present the model of performance and training of the actor adopted in Europe at the end of the 19th Century, in order to contextualize the theatrical atmosphere against which the main othernormative theater of the 20th Century protested. In the end, we stand out, briefly, the contributions that François Presença, Émilie Jacques Dalcroze and the Oriental Theater offered for this renewal.

Key-words: renewal theater, theater 19th Century

Título: El contexto europeo de formación y actuación en el pasaje del siglo XIX al siglo XX

Resumen: este artículo tiene como objetivo presentar el modelo de actuación y formación del actor, adoptado en Europa a fines del siglo XIX, para entender el contexto del ambiente teatral contra el cual los principales renovadores teatrales del siglo XX se opusieron. En el final de este artículo, destacamos, de modo sucinto, las contribuciones que François Delsarte, Émilie Jacques-Dalcroze y el Teatro Oriental ofrecieron para esta renovación.

Palabras-clave: renovación teatral, teatro del siglo XIX.

Já foi dito a respeito das transformações operadas na passagem do século XIX para o século XX que "tudo o que era sólido se desmancha no ar" (MARX, 1988), tamanho o alcance das modificações que a modernidade produziu sobre a vida em sociedade. ${ }^{1}$ Influenciadas por esse ambiente, as correntes modernas de teatro alteraram profundamente o modo de fazer e pensar essa arte no ocidente. Em pouco mais de 60 anos, propostas de renovadores como Konstantin Stanislávski, Vsevolod Meyerhold, Gordon Craig, Adolphe Appia, Antonin Artaud, Jacques Copeau, Erwin Piscator, Bertolt Brecht, Luca Ronconi e Jerzy Grotowski reformularam completamente a prática teatral e a forma do teatro se relacionar com o texto, com o espaço e com o 
espectador. Intensas e diversificadas, essas experiências influenciaram diretamente o "teatro contemporâneo" e ainda hoje são referências fundamentais para os principais criadores e estudiosos teatrais de todo o mundo.

Este artigo pretende apresentar alguns paradigmas que baseavam o trabalho do ator na Europa, na passagem do século XIX para o século XX, assim como abordar as condições de produção teatral e formação dos atores nesse período para, em seguida, apresentar o movimento de renovação que levou à constituição de um novo conjunto de paradigmas para a arte do ator. Não é nossa intenção comparar esses dois momentos da história do teatro, até mesmo porque, como cada época possui sua forma própria e particular de criar e produzir, seria um erro olhar para o passado a partir de valores do presente. Nosso intuito, portanto, é apenas oferecer um "panorama" que permita identificar algumas características do modelo de atuação e formação do ator nesse momento de grandes transformações.

\subsection{O modelo europeu de atuação e formação do ator na passagem do séc. XIX para o XX}

Na Europa do final século XIX, o modelo dominante de atuação era caracterizado pelo representar. Dentro desse modelo, a interpretação baseava-se em um conjunto limitado de códigos, poses e gestos que correspondiam a determinados sentimentos e situações. Assim, para cada sentimento ou estado que o intérprete desejasse representar, havia um gesto ou pose correspondente. Tais códigos foram definidos pelos atores mais experientes e por suas companhias, sendo transmitidos de geração a geração. Dessa forma, segundo esta tradição de interpretação, bastava o ator reproduzir tais poses e atitudes nas situações adequadas e a "personagem" estava pronta.

Como lembra Nicolau Evreinoff (Apud ASLAN, 1994, p. 135), na Rússia, no tempo de Pedro, o Grande, o ator colocava o público a par de seu estado afetivo e depois se exprimia com gestos demonstrativos: por exemplo, "para traduzir a cólera rasgava as vestes, ia e vinha como uma fera enjaulada, virava os olhos furibundos".

Para a historiadora do teatro Odete Aslan (1994), nesse período, o escasso número de ensaios e a alta rotatividade dos espetáculos incitavam os atores a basearem suas interpretações em estereótipos. Outro recurso bastante em voga, ainda segundo essa historiadora, era o apelo à dramaticidade desmedida: "Declamavam com ênfase e sorviam por vezes na embriaguez o gênio da inspiração. Exteriorizavam-se até a histeria, abandonando-se ao gesto eslavo do sofrimento, utilizando efeitos fáceis, derramando suas lágrimas com abundância” (ASLAN, 1994, p. 72). 
Quanto ao modelo de produção teatral vigente na época, pode-se dizer que, em diversos casos, a produção teatral foi baseada em companhias teatrais familiares e itinerantes. Sobre esse modelo, Grotowski (2007, p. 222) lembra que nas companhias da Europa central e oriental,

[...] o pai e a mãe eram atores, o velho tio era o diretor, mesmo se na realidade a sua função se limitasse a indicar aos atores: "você deve entrar por esta porta e sentar-se naquela cadeira", além disso cuidava dos detalhes do figurino e dos acessórios quando era necessário. $\mathrm{O}$ sobrinho era ator e, quando se casava, a mulher também tornava-se atriz; se depois chegava um amigo, se unia à família teatral. Essas famílias tinham um brevíssimo período de ensaios, mais ou menos cinco dias, para preparar uma novidade. Assim os atores daquele tempo tinham desenvolvido uma memória prodigiosa: aprendiam o texto com grande rapidez e em poucos dias eram capaz de dizê-lo de cor. Mas, visto que às vezes se confundiam, era necessário o ponto.

Outra característica marcante desse teatro foi a especialização dos papéis segundo tipos pré-estabelecidos: o vilão, o herói, o galã, a dama centro, etc. Assim, no interior das companhias teatrais, cada ator dominava o conjunto específico de códigos e "clichês" necessários para a representação do seu papel-tipo. Essa especialização do trabalho do ator segundo papéis dramáticos permitia às companhias teatrais da época uma grande agilidade na preparação de "novas" montagens, fato decisivo para a sobrevivência das companhias que dependiam da constante renovação dos repertórios para atrair público e fazer bilheteria. Entretanto, essas montagens, se bem observadas, quase sempre giravam em torno das mesmas personagens e das mesmas situações dramáticas - não passando, em sua grande maioria, de variações sobre temas e situações recorrentes.

Já no que se refere à organização das companhias teatrais, pode-se dizer que quase sempre estavam organizadas hierarquicamente de forma vertical a partir do seu primeiro-ator, normalmente ocupante do posto de maior destaque nas companhias. A esse ator cabia, por direito, a representação dos papéis principais e, quando este ator obtinha alguma fama e reconhecimento junto ao público, tornava-se a "vedete" da companhia - posição que lhe garantia uma série de regalias e privilégios, dentro e fora de cena.

No teatro europeu de então, grandes vedetes movimentavam a cena teatral e garantiam o sucesso comercial de suas companhias. Personalidades como Sarah Bernhardt, Julia Bartet, Mounet-Sully e Réjane (na França); Ellen Terry e Henry Irving (na Inglaterra); Eleonora Duse (na Itália), foram conhecidas como "monstros sagrados" do teatro de seu tempo e gozavam de grande fama e popularidade. 
Apoiada sobre uma elaborada técnica pessoal de interpretação, via de regra "vocal”, já que a ênfase da atuação estava na declamação dos papéis, a interpretação destes grandes atores estava quase que inteiramente baseada no poder de arrebatamento carismático de suas personalidades em cena. Assim, toda uma "cultura" paralela aos palcos foi criada entorno da figura da vedete, que passou a ser a principal responsável pelo sucesso ou fracasso de uma bilheteria. Neste ponto, vale observar que o público afluía aos teatros para apreciar mais o desempenho espetacular que o "talento" e "genialidade" que esses grandes atores imprimiam às suas interpretações pessoais, do que propriamente para apreciar esta ou aquela montagem deste ou daquele texto teatral em específico.

A preponderância da vedete em cena e o papel de destaque que ocupava dentro das companhias contribuem para explicar a elevada dose de exibicionismo e narcisismo presente em suas interpretações, outra característica marcante da época. Essas qualidades peculiares das vedetes marcavam o teatro de então e constituíam o grande chamariz das produções, o diferencial das montagens mais badaladas.

Por fim, resta observar que, dada a natureza da personalidade da vedete ser completamente rebelde à ideia de submeter-se à disciplina predeterminada por uma direção externa, a arte do monstro sagrado fazia com que ele fosse quase sempre o seu próprio diretor. Muitas vedetes eram, inclusive, elas mesmas as proprietárias de suas companhias.

Já no que se refere à formação do ator na França, Odete Aslan destaca a existência de duas "escolas" no período. A escola do "Conservatório" que, por estar voltada à formação de intérpretes para os papéis clássicos da Comédie-Française, iniciava seus alunos dentro da tradição do "falar bem" e do "colocar-se bem" em cena herdada dos seus grandes atores. E a "escola da vida" que formava seus atores a partir da experiência prática que obtinham através de "figurações", "pontas", “substituições” e finalmente papéis. Como lembra Aslan (1994, p. 3):

As marcações eram simples: levantar-se, dar três passos à frente para proferir uma fala diante do ponto (Dullin reconhecia ter aprendido tudo na escola do Melodrama). As personagens correspondiam a tipos convencionais. Em suma, era preciso somente dizer o texto com certa desenvoltura e conhecer alguns truques para "tirar efeitos".

Assim, dentro desse modelo de formação, ao aprendiz não havia outra saída senão escolher entre o respeito a uma tradição instituída e formalizada ou a aventurar-se no empirismo mais desenvolvido. Em ambas as escolas, entretanto, a ênfase da formação recaia sobre o poder de persuasão da oratória e sobre o refinamento da gestualidade do ator. Também aqui ficou evidente a 
influência do modelo de interpretação adotado pelas vedetes sobre a formação dos jovens atores, que se dedicavam a uma aprendizagem por espelhamento dos grandes nomes do teatro da época.

Como vimos até aqui, o grande modelo de atuação vigente na Europa do final do século XIX era o da representação, modelo este amparado no largo uso de "clichês" e na construção de personagens-tipo estereotipadas e exteriorizadas. Com os holofotes direcionados sobre a figura do ator-vedete, sua forma de atuação, além de reforçar ainda mais o estilo de representação "carregada" e "afetada", representou o grande modelo segundo o qual se iniciavam os jovens atores - um modelo baseado nos valores românticos da inspiração, do talento e da genialidade, ou seja, em "valores" exclusivamente ligados à personalidade nata do ator. Ao diretor cabia o papel, quando existia, de organizador da cena.

No que se refere ao grau de domínio técnico do ator sobre o seu instrumento de trabalho, o oficio do ator, enquanto artista criador, estava longe de se equiparar ao do pintor, ao do artesão ou ao do escultor, pois, como descrito acima, sua criação estava baseada em valores pouco objetivos e controláveis. Pode-se mesmo pensar que, para o ator a dimensão "artística" de sua profissão (pelo menos no sentido que hoje adquiriu a conotação da palavra artista) era de pouca relevância. Mesmo ao Teatro cabia um papel menor dentro das Artes, quase sempre subalterno à Literatura. ${ }^{2}$

\subsection{A necessidade de renovação do teatro e o ator como sua especificidade}

A partir do fim do século XIX, o teatro começou a dar sinais da necessidade de expandir seus horizontes, de buscar novos rumos e de se reinventar. Outros aspectos do teatro, que não os literários, começaram a ser valorizados, assim como se multiplicaram as interpretações sobre a origem do teatro. A arte teatral passou então a buscar uma realização que atendesse a seus elementos primitivos, da forma mais integral possível. Adolphe Appia, Gordon Craig, Vsevolod Meyerhold, Alexander Tairov e tantos outros foram paladinos dessa exigência de reforma; todos eles inspirados pelo que se convencionou chamar de teatro teatral. Como observa Bornhein (1992, p. 15):

Os novos ideais faziam vacilar as próprias bases do realismo. O que esses autores combatem é precisamente a ideia de ilusão cênica, tudo aquilo que pretende fazer do palco a própria realidade; lutar por um teatro teatral é lutar por algo que aceita o teatro por aquilo que é: teatro. [...] o seu ideal comum é a "reteatralização" do teatro. Todo o trabalho do ator, a utilização dos elementos cênicos e sobretudo a concepção do espetáculo deveriam obedecer a critérios radicalmente novos; critérios que derivariam das exigências especificas da arte teatral, das dimensões propriamente cênicas do teatro. 
Nesse sentido, Appia (1911, p. 156), refletindo sobre as dimensões propriamente teatrais do teatro, foi um dos primeiros a afirmar que "O Teatro intelectualizou-se" e a lembrar, em consequência, que "o corpo não é mais do que portador e representante de um texto literário e só nesta qualidade se dirige aos nossos olhos". Contrapondo-se à concepção de teatro como o resultado da soma de todas as artes envolvidas na produção da cena, foi um dos primeiros pensadores do fenômeno teatral a definir o teatro como uma "obra de arte viva" e a defender a "presença viva do ator em cena" como a sua especificidade. Suas ideias propagavam a necessidade de se "voltar ao princípio, isto é, aos fatores de qualquer maneira primordiais: a presença do corpo criando o Espaço e o Tempo vivos e a instauração da música nesse corpo para operar a modificação estética que é própria da obra de arte" (APPIA, 1911, p. 161).

\subsection{A reação dos Renovadores}

Durante o século XX, propostas de renovadores como Stanislávski, Meyerhold, Craig, Copeau, Grotowski, Brecht e Artaud surgem como resposta ao convencionalismo que dominava os palcos de então e se apresentam como uma reação contra seus princípios tradicionais e contra as banalidades e o exibicionismo em voga. Como observa Jean-Jacques Roubine (1988, p. 170), as grandes teorias da representação do século XX apoiaram-se, no Ocidente, quase sempre na rejeição da interpretação tradicional e todos os esforços, desde Stanislávski, visavam a essa necessária reformulação da técnica da arte do ator.

Odete Aslan (1994, p. 47), analisando o novo modelo de formação do ator proposto no século XX, observa que:

Ante as deficiências de ensino, todos os homens de teatro tiveram a mesma reação: criar um grupo de trabalho para experimentar em seu âmbito métodos de reeducação teatral. A Escola do Vieux-Colombier de Jacques Copeau [na França], o Estúdio de Stanislávski no Teatro de Arte de Moscou, e o Laboratório de Grotowski em Opole [Polônia] surgiram do mesmo desgosto em relação aos modelos de formação existentes, do mesmo desejo de retirar-se momentaneamente para dedicar-se à pesquisa, da mesma necessidade de refugiar-se em um falanstério para evitar as más ambições.

Ao enfatizar e desenvolver o trabalho técnico do ator, estas propostas de formação proporcionaram uma nova atitude do ator para com sua profissão, pois em comum portavam a rejeição aos valores românticos que orientavam o trabalho do ator de seu tempo. O primado da técnica do trabalho do ator sobre si mesmo, desloca valores como "talento", "inspiração" e 
"genialidade", e lançam um novo paradigma para a arte do ator, baseado no controle técnico, na disciplina e no treinamento do aparelho psicofísico do ator.

\subsection{Precursores}

Essas propostas de renovação, entretanto, apoiaram-se em teorias e práticas disponíveis em seu tempo para se consolidarem. Como observa Matteo Bonfitto, em seu livro O Ator Compositor, três nomes foram fundamentais para se lançar as bases que permitiram a emergência de um novo ator: François Delsarte, Émilie Jacques-Dalcroze e os Teatros Orientais.

Delsarte (1811-1871) teve um papel fundamental na história das artes cênicas, não como realizador de obras, mas como responsável pela transformação da percepção e das categorias utilizadas para pensar e realizar o trabalho artístico. Movido pela necessidade de descobrir como as pessoas agem, movem-se e falam em todas as situações emocionais de suas vidas, Delsarte dedicou anos de sua vida a uma minuciosa observação em parques, trens e em diferentes ambientes profissionais, até inferir o que chamou de "Lei da Correspondência". Segundo essa lei, cada função espiritual corresponde a uma função do corpo; a cada grande função do corpo corresponde um ato espiritual. A partir dessa correspondência, é possível pensar que todas as qualidades espirituais invisíveis se tornam visíveis através do homem, ou seja, todas as qualidades subjetivas encontram no corpo uma expressão correspondente e são passíveis de serem fisicamente codificadas (não a partir de clichês, mas de códigos corporais). Com isso, ele desloca o pensar sobre o homem e, consequentemente, sobre o ator, do polo da representação ao polo da expressão - um deslocamento que estará na base de futuras elaborações sobre o trabalho do ator, entre as quais a do próprio Stanislávski, pois, como observa Bonfitto: “Com a passagem da representação à expressão, concretizada por Delsarte, não somente materializa-se a dimensão dos processos interiores, como também passa-se a constatar a sua ligação com a dimensão física do homem. A conexão internoexterno concretiza-se enfim" (2002, p. XVII).

Dalcroze (1865-1950), adotando a conexão elaborada por Delsarte, desenvolve sua Eurítmica e aprofunda a reflexão sobre as possibilidades expressivas do homem e do ator a partir de um elemento que estará no centro de muitas teorias e poéticas: o ritmo. "O ritmo passa a ser o eixo da relação entre o corpo e a música, tornando-se assim um elemento produtor de sentido" (BONFITTO, 2002, p. XIX). 
Durante o século XX um aspecto do teatro oriental influencia de maneira decisiva o trabalho de artistas como Stanislávski, Meyerhold, Brecht, Copeau, Grotowski, Eugenio Barba e Peter Brook, e esse aspecto é o ético. Segundo Bonfitto (2002, p. XIX), “a conexão [nesses trabalhos] entre a percepção e a ética é evidente. Tais criadores mostraram como, sem a atitude adequada ao trabalho criativo, não se tornam possíveis as descobertas artísticas".

As conexões entre a dimensão interior e exterior na expressão humana, entre a ética e a percepção e a importância do ritmo, forneceram instrumentos que contribuíram para o surgimento de sistemas e teorias essenciais à construção de um ator mais consciente dos elementos e da complexidade do seu ofício. Tais referências foram, portanto, fundamentais para a construção de um novo olhar sobre o trabalho do ator.

Inevitavelmente, a partir do momento em que um novo teatro precisasse de um novo ator, o vedetismo teria de ser revisto. Como observa Roubine (1998, p. 204), em função das novas exigências e paradigmas do teatro no século XX:

O ator de hoje é portanto, logicamente menos espetacular, porém mais virtuosístico. É capaz de representar a frio, de desmontar e desmascarar o seu personagem. Dá prioridade à reflexão, mais do que ao instinto. Representa com ironia, mais do que com emoção. Essas suas virtudes são diametralmente opostas às da vedete, que se impõem justamente através de seu phatos. Levado às ultimas consequências, esse ator novo é um ator sem rosto e sem voz - o que não quer dizer sem personalidade. Ele domina técnicas pouco familiares às vedetes, cuja arte é sobretudo uma estilização da dicção e uma vocalização. Técnicas acrobáticas do corpo, trabalho com máscara facial (Grotowski) ou representação com verdadeiras máscaras, exploração dos diversos registros da voz e, de modo mais geral, de tudo aquilo que poderíamos chamar a teatralidade do corpo. Era para essa direção que Artaud sonhava conduzir o ator de seu tempo; era nessa direção que Meyerhold havia, embora por pouco tempo, se engajado. Era também nesse sentido que Brecht fazia trabalhar os seus atores do Berliner Ensemble, e Ariane Mnouchkine faz trabalhar os do Théâtre du Soleil. Sejam as técnicas adotadas novas (Grotowski) ou tradicionais (o circo, a commedia dell'arte, etc.), em todos os casos trata-se de práticas coletivas que excluem o individualismo e o narcisismo inerentes à atuação da vedete. Pois aqui o multifacetado virtuosismo que esta sendo desenvolvido não constitui por si só uma finalidade. Trata-se de fazer do ator um instrumento eficiente. Instrumento disponível para as experiências mais variadas e audaciosas. Capaz de fazer aparecer todas as formas de teatralidade.

\section{Referências}

APPIA, Adolphe. A obra de arte viva. Trad. Redondo Júnior. Lisboa: Arcádia, 1911.

ASLAN, Odete. O ator no século XX. São Paulo: Perspectiva, 1994.

BONFITTO, Matteo. O Ator Compositor. São Paulo: Perspectiva, 2002. 
BORNHEIN, Gerd. O sentido e a máscara. São Paulo: Perspectiva, 1992.

GROTOWSKI, Jerzy. In: FLASZEN, Ludwik; POLLASTRELLI, Carla (Orgs.). O Teatro Laboratório de Jerzy Grotowski 1959-1969. São Paulo: Perspectiva: SESC São Paulo; Pontedera, It: Fundazione Pontedera Teatro, 2007.

MARX, Karl. O manifesto do Partido Comunista. Petrópolis: Vozes, 1988.

ROUBINE, Jean-Jacques. Linguagem da encenação teatral 1880-1980. Rio de Janeiro: Jorge Zahar, 1998.

\footnotetext{
${ }^{1}$ As transformações produzidas pela "modernidade", advindas do desenvolvimento da industrialização e decorrentes do crescimento dos grandes centros urbanos, repercutiram diretamente sobre o caminho que a Arte tomou no século XX. No campo teatral, podemos citar o impacto da invenção do cinema, que tomou do teatro a prerrogativa de apresentar a mímesis da realidade, como a fotografia tomou da pintura o registro da realidade. O uso da iluminação elétrica nos teatros, como se sabe, também transformou profundamente a relação entre a cena e a sala de audiência. A ampliação dos equipamentos culturais e a estabilização dos teatros públicos e privados alavancaram a atividade teatral, que ganhou em escala e em grau de profissionalização técnica de seus artífices, inclusive os intérpretes. O mesmo podemos dizer a respeito da criação de escolas para a formação de atores em toda a Europa e sobre a instituição de companhias estáveis por todo o mundo. Todas essas mudanças repercutiram diretamente sobre o "fazer teatral", fazendo com que, aos poucos, o teatro e o ofício do ator se equiparassem às demais artes no que diz respeito ao nível de sofisticação técnica.

${ }^{2}$ Não pretendemos afirmar que os atores fossem desprovidos de técnica, pois, para contradizer essa ideia, bastaria observar o alto grau de elaboração técnica dos grandes atores da época. Chamamos a atenção para o fato de que o modelo de atuação apoiava-se quase sempre em valores subjetivos, pouco controláveis e quase sempre à mercê da personalidade de cada ator. Há muitos registros que descrevem atuações extraordinárias de muitas vedetes, mas há também o registro de que muitas destas atuações tiveram dificuldade de se repetir ou de se manter no tempo. Outro ponto que destacamos é que, pelas características destacadas, tais "técnicas" de representação, por mais refinadas e elaboradas que fossem, sofriam por serem incapazes de serem transmitidas: como ensinar um jovem ator a se inspirar, a ser talentoso?
} 